\title{
Reasons for Alcohol Dependence and Their Relationship with Addiction Beliefs, Attitude and Severity: A Cross-Sectional Study
}

\author{
Harini K.C ${ }^{1}$, RavishaThunga A $^{2}$ \\ ${ }^{1}$ Junior resident, Department of Psychiatry, A.J. Institute of Medical Sciences, Mangalore, ${ }^{2}$ Professor and HOD, Department of Psychiatry, A.J. Institute of Medical \\ Sciences, Mangalore.
}

\section{Abstract}

Background: Alcohol abuse is a complex problem because there are so many reasons why people fall into substance abuse in the first place. Unless all these reasons are considered, it will be difficult to effectively tackle the problem. The severity of dependence may be a direct consequence of the addiction beliefs and attitude of the person toward alcohol intake. Addiction beliefs and attitude about the substance can influence the reasons which are attributed for the substance dependence. This study has examined the various reasons for substance use and correlation of reasons for substance use with socio-demographic data, alcohol dependence severity, addiction beliefs in people with different attitudes. Subjects and Methods: It is a cross-sectional study done at A.J. Institute of Medical Sciences, Mangalore. After obtaining the ethical clearance the study was started. Simple random sampling technique (lottery method) was adopted to select the study participants. 90 study participants who met the inclusion criteria were enrolled in the study. The sample collection was done from December 2016 to November 2017. After obtaining a written informed consent, patients were screened for cognitive impairment with the help of Hindi mental status examination and then they were further evaluated using Socio demographic clinical proforma, Modified version of reasons for substance use scale (ReSUS), Addiction belief scale (ABS), Alcohol dependence scale, The scale for assessment of attitudes toward drinking and alcoholism, second version (SAADA II). Results: More the severity of dependence more are the reasons quoted. A significantly high number of people with attitude of rejection have quoted social enhancement as reasons for substance abuse. People with more severe dependence believe less in free -will model. People who believe in free-will model have more rejection kind of attitude. Conclusion: These findings have a direct implication on the prevention and treatment of alcohol dependence in the Indian context. Discussing the treatment options and providing proper psychological interventions would be more acceptable than emphasizing on pharmacological therapies alone. Primary prevention should be planned to fit the needs of the people.

Keywords: Alcohol dependence; addiction beliefs; reasons for alcohol use; attitude.

Corresponding Author: Dr. RavishaThunga A, Professor and HOD, Department of psychiatry, A.J. institute of medical sciences, Mangalore.

Received: March 2019

Accepted: March 2019

\section{Introduction}

Developing countries like India experience more problems with alcohol abuse than developed countries, despite equal amounts of drinking. ${ }^{[1]}$ Overall $5.1 \%$ of the global burden of disease and injury is attributable to alcohol, as measured in disability-adjusted life years (DALYs). ${ }^{[2]}$ Far too many people, their families and communities suffer the consequences of the harmful use of alcohol through violence, injuries, mental health problems and diseases like cancer and stroke. It's time to step up action to prevent this serious threat to the development of healthy societies. ${ }^{[3]}$ Alcohol abuse is a complex problem because there are so many reasons why people fall into substance abuse in the first place. Unless all these reasons are considered, it will be difficult to effectively tackle the problem. ${ }^{[4]}$

Patients believing in free-will model are more amenable to change. The severity of dependence may be a direct consequence of the addiction beliefs and attitude of the person toward alcohol intake. Addiction beliefs and attitude about the substance can influence the reasons which are attributed for the substance dependence. ${ }^{[5]}$

A better understanding of the reasons as to why people use alcohol is essential if effective interventions aimed at reducing alcohol use are to be developed. Further research is necessary to explore the extent to which different reasons for use are related to demographic variables, Addiction beliefs, Attitudes and alcohol dependence severity. Understanding various dynamic factors involved in substance abuse can aid in formulating effective strategies in preventing and treating them. ${ }^{[5]}$

\section{Subjects and Methods}

After obtaining ethical committee clearance, the study was conducted in a tertiary care hospital catering Dakshina Kannada and neighbouring districts with a cross-sectional design. The study population included patients who have been referred to the department of psychiatry. Patients fulfilling the ICD-10 diagnostic criteria of mental and 
behavioural disorders due to alcohol dependence syndrome, with active dependence in the age group of 18-65 years, educated uptoatleast primary education were taken, excluding those having any other substance abuse (except tobacco and caffeine), cognitive impairment, psychosis or severe depression. The subjects were assessed with sociodemographic clinical proforma, modified version of reasons for substance use scale, ${ }^{[6]}$ Addiction belief scale, ${ }^{[7]}$ alcohol dependence scale and scale for assessment of attitudes toward drinking and alcoholism- second version. ${ }^{[8,9]}$

\section{Results}

Karl Pearson correlation coefficient was calculated to find the significant relationship between the various parameters. Level of significance in this study was 0.05 and analysis was carried out using Statistical Package for the Social Sciences (SPSS) software, version 17. Analysed data was represented in the form of tables and diagrams.

The study findings point towards, more the dependence more are the reasons quoted for alcohol use. [Table 1 and
Figure 1]. Alcohol dependence severity more significantly correlated with individual enhancement as reason for alcohol use with $\mathrm{p}<0.001$, Whereas dependence severity significantly correlated with social enhancement as reason for substance use with $\mathrm{p}<0.005$. [Table 1 and Figure 1]

Subjects who had more severe alcohol dependence score believed less in free will model with $\mathrm{p}<0.001$. [Table 2 and Figure 2] Study participants who had attitude of rejection towards alcohol believed in free will model with $\mathrm{p}<0.001$. [Table 2 and Figure 3]

People who predominantly quoted social enhancement as reasons for substance abuse, had significant negative correlation with attitude of rejection. [Table 3 and Figure 4]

Table 1: Correlation between alcohol dependence severity and reasons for alcohol use

\begin{tabular}{|l|l|}
\hline Reasons for alcohol use & $\begin{array}{l}\text { Alcohol dependence severity } \\
\text { (r value) }\end{array}$ \\
\hline Coping with distressing emotions & .467 \\
\hline Social enhancement & $.503^{*}$ \\
\hline Individual enhancement & $.570^{* *}$ \\
\hline$* \mathrm{p}<0.005, * * \mathrm{p}<0.001$ & \\
\hline
\end{tabular}

Table 2: Correlation between addiction beliefs with alcohol dependence severity and Attitude

\begin{tabular}{|l|l|l|l|l|l|l|}
\hline & $\begin{array}{l}\text { Free will } \\
\text { model }\end{array}$ & $\begin{array}{l}\text { Alcohol dependence } \\
\text { severity }\end{array}$ & $\begin{array}{l}\text { Attitude of } \\
\text { acceptance }\end{array}$ & $\begin{array}{l}\text { Attitude of } \\
\text { rejection }\end{array}$ & $\begin{array}{l}\text { Attitude of } \\
\text { avoidance }\end{array}$ & $\begin{array}{l}\text { Attitude of social } \\
\text { dimension }\end{array}$ \\
\hline Free will model & 1 & $-.424 * *$ & -.019 & $.322 * *$ & .109 & -.006 \\
\hline$* * \mathrm{p}<0.001$ &
\end{tabular}

Table 3: Correlation between attitude of rejection and reasons for alcohol use

\begin{tabular}{|l|l|}
\hline Reasons for alcohol use & Attitude of rejection (r value) \\
\hline Coping with distressing emotions & .023 \\
\hline Social enhancement & $-.377 * *$ \\
\hline Individual enhancement & -.337 \\
\hline $\mathrm{p}<0.005 * * \mathrm{p}<0.001$ & \\
\hline
\end{tabular}

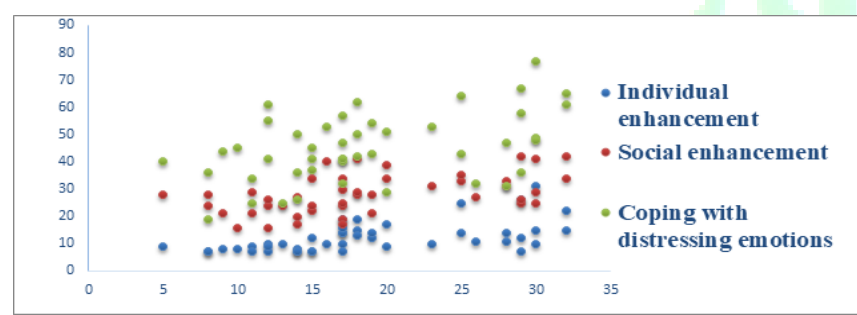

Figure 1: Correlation between alcohol dependence severity and reasons for alcohol use

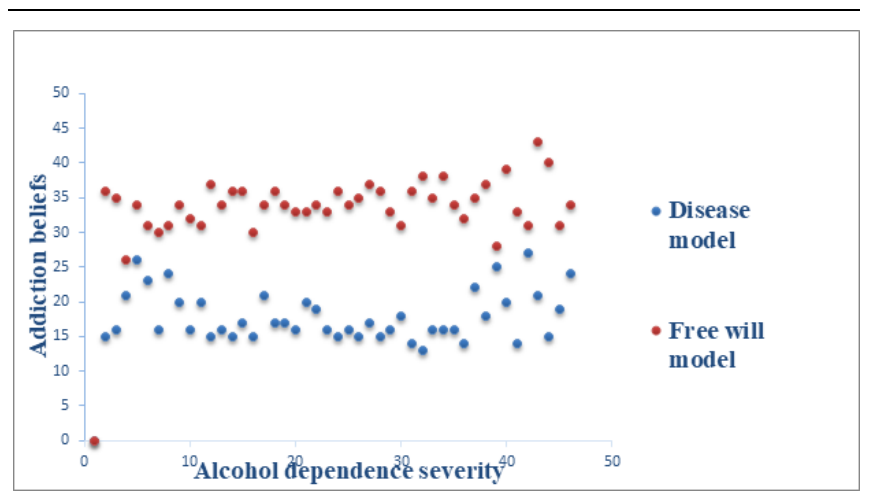

Figure 2: Correlation between alcohol dependence severity and addiction beliefs

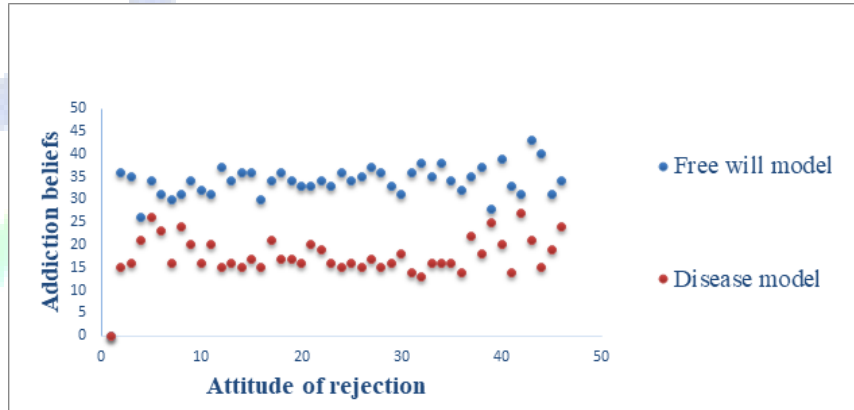

Figure 3: Correlation between attitude of rejection and addiction beliefs

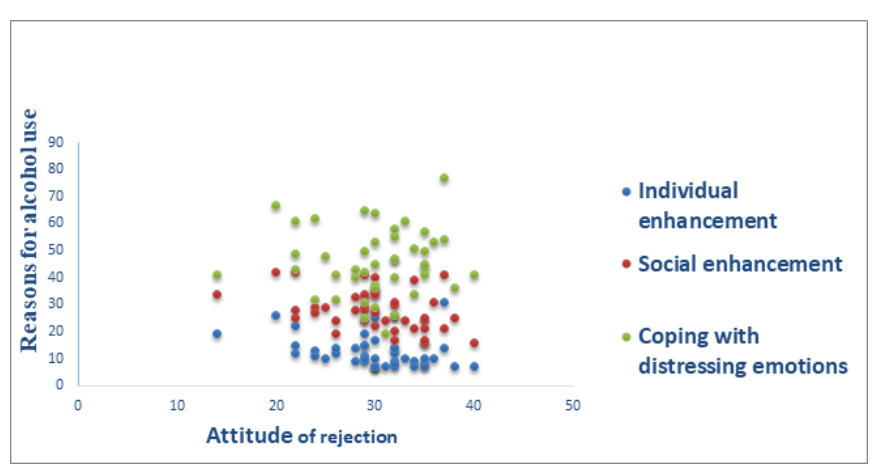

Figure 4: Correlation between attitude of rejection and reasons for alcohol use

\section{Discussion}

The study findings point towards, more the dependence more are the reasons quoted for alcohol use. A significantly 
higher reasons for consuming alcohol was quoted for individual enhancement. Individual enhancement was quoted more as compared to social enhancement and coping with distressing emotions.

Findings are in line with the study conducted by Smith M J et al, who could establish three different reasons for drinking alcohol - drink to cope, drink to be sociable, drink to enhance social confidence. ${ }^{[10]}$ And the reasons for drinking in turn differentially predicted multiple indicators of quantity and frequency of alcohol consumption. ${ }^{[10]}$

Findings are in line with the study conducted by VS Sreeraj et al (2012). ${ }^{[11]}$ However, this study showed that tribals cited reasons associated with social enhancement and coping with distressing emotions rather than individual enhancement, which was found in non-tribals. ${ }^{[11]}$

These findings are also supported by study conducted by Abbey A et al, which found two motives for alcohol consumption. There was a significant interaction between drinking to cope with stress and perceived stress, and there was also a significant interaction between drinking for social reasons and friend's alcohol consumption1. ${ }^{[12]}$

Similar findings were obtained in a study conducted by Emmanuel Kuntsche et al in 2014. They conducted a study to test the structure and endorsement of drinking motives and their link to alcohol use among adolescents from 13 European countries, where Social motives for drinking were most frequently indicated followed by enhancement, coping and conformity motives, in that order. ${ }^{[13]}$

Similar findings were obtained in a study conducted by Blevins CE et al in 2016 where they evaluated paths from risk factors for alcohol use, motives for drinking and subsequent outcomes for alcohol use. Study indicated that expectancies, maladaptive coping and negative affect personality styles are associated with coping motives for drinking, and that coping motives are significantly related to problems associated with use. ${ }^{[14]}$

Findings are in line with a study conducted by Enoch et al, where they correlated the role of early life stress as a predictor for alcohol dependence and they found that, early onset of problem drinking in adolescence and alcohol and drug dependence in early adulthood can result in permanent neuro-hormonal changes. ${ }^{[15]}$

Findings are also supported by a study conducted by Keyes et al, where they correlated stressful life experiences with alcohol dependence. Where he correlates alcohol dependence with coping with stressful situations like catastrophic events, child maltreatment, common adult stressful life events and minority stress. ${ }^{[16]}$

People with more severity of dependence believe less in free will model and think that relying on their will power and learning new ways to cope with life will not lead them to overcome dependence. This also meant a stronger belief in disease model, which makes them realise the need for pharmacotherapy, which in turn can improve their compliance to medicines.

However, patients believing in free-will model are more amenable for change. ${ }^{[1]}$ People with more severe dependence have significantly quoted individual enhancement as reasons for alcohol use and they believe less in free will model. People with attitude of rejection have quoted social enhancement as reasons for substance abuse. A lower score on this factor would indicate agreement with the items and hence unfavourable (negative) attitude. ${ }^{[9]}$ Belief in free will model was noted to be stronger in people with rejection attitude, without any correlation with the reason for intake.

\section{Conclusion}

The reasons attributed by the patients and the interventions would be based on the addiction belief and attitude of the patient with regard to the problem related to alcohol. By just finding out the reasons attributed for alcohol abuse and by addressing them we can motivate people to change their ways of life and their ability to tackle stress.

Attitudinal characteristics importantly influence one's propensity to acquire knowledge, skills and to learn new behaviour, fostering proper attitudes towards drinking an alcoholism. Discussing the treatment options and providing proper psychological interventions would be more acceptable than emphasizing on pharmacological therapies alone.

The findings from this study can aid in planning comprehensive management strategies for the patients with substance use disorders and for their burden-ridden families.

\section{References}

1. Saxena S. Country profile on alcohol in India. Alcohol and Public Health in.1999; 8:37-60.

2. WHO Alcohol fact sheet September 2018. http://www.who.int/newsroom/fact-sheets/detail/alcohol

3. WHO Global status report on alcohol and health 2018. http://www.who.int/substance_abuse/publications/global_alcohol_repo $\mathrm{rt} / \mathrm{en} /$

4. Available from:http://alcoholrehab.com/

5. Sreeraj VS, Prasad S, Khess CR, Uvais NA. Reasons for substance use: A comparative study of alcohol use in tribals and non tribals. Indian journal of psychological medicine.2012Jul;34(3):242.

6. Gregg L, Barrowclogh C, Haddock G. Development and validation of a scale for assessing reasons for substance use in schizophrenia: the ReSUS scale. Addictive behaviours.2009 oct31;34(10):830-37.

7. Schaler JA. Addiction beliefs of treatment providers: Factors explaining variance.Addiction Research.1997 jan1;4(4):367-84.

8. Skinner HA,Horn JL. Alcohol dependence scale users guide. Addiction Research Foundation;1984.

9. BasuD,MalhotraA,Varma VK, Malhotra R. Development of a scale to assess attitudes toward drinking and alcoholism. Indian journal of psychiatry.1998 Apr;40(2):158.

10. Smith MJ, Abbey A, Scott RO. Reasons for drinking alcohol: Their relationship to psychosocial variables and alcohol consumption. International Journal of the Addictions. 1993 Jan 1;28(9):881-908.

11. Sreeraj VS, Prasad S, Khess CR, Uvais NA. Reasons for substance use: A comparative study of alcohol use in tribals and non tribals. Indian journal of psychological medicine.2012jul;34(3):242.

12. Abbey A, Smith MJ, Scott RO. The relationship between reasons for drinking alcohol and alcohol consumption: An interactional approach. Addictive behaviors. 1993 Nov 1;18(6):659-70.

13. Kuntsche E, Gabhainn SN, Roberts C, Windlin B, Vieno A, Bendtsen P, Hublet A, Tynjala J, Valimaa R, Dankulincova Z, Aasvee K. Drinking motives and links to alcohol use in 13 European countries, Journal of Studies on alcohol and drugs. 2014 May;75(3):428-37.

14. Blevins CE, Abrantes AM, Stephens RS. Motivational pathways from 
antecedents of alcohol use to consequences: A structural model of using alcohol to cope with negative affect. The American journal of drug and alcohol abuse. 2016 Jul 3;42(4):395-403.

15. Enoch MA. The role of early life stress as a predictor for alcohol and drug dependence. Psychopharmacology. 2011 Mar 1;214(1):17-31.

16. Keyes KM, Hatzenbuehler ML, Hasin DS. Stressful life experiences, alcohol consumption, and alcohol use disorders: the epidemiologic evidence for four main types of stressors. Psychopharmacology. 2011 Nov 1;218(1):1-7.

Copyright: (C) the author(s), 2019. It is an open-access article distributed under the terms of the Creative Commons Attribution License (CC BY 4.0), which permits authors to retain ownership of the copyright for their content, and allow anyone to download, reuse, reprint, modify, distribute and/or copy the content as long as the original authors and source are cited.

How to cite this article: Harini KC, Thunga AR. Reasons for Alcohol Dependence and Their Relationship with Addiction Beliefs, Attitude and Severity: A Cross-Sectional Study. Asian J. Med. Res. 2019;8(1):PY10-PY13.

DOI: dx.doi.org/10.21276/ajmr.2019.8.1.PY3 